\title{
Chemo-mechanical softening during in situ nanoindentation of anodic porous alumina with anodization processing
}

\author{
Chuan Cheng ${ }^{\text {a) }}$ and A. H. W. Ngan \\ Department of Mechanical Engineering, The University of Hong Kong, Pokfulam Road, Hong Kong
}

(Received 22 December 2012; accepted 18 April 2013; published online 8 May 2013)

\begin{abstract}
Simultaneous application of mechanical stresses on a material as it undergoes an electrochemical reaction can result in interesting coupling effects between the chemical and mechanical responses of the material. In this work, anodic porous alumina supported on $\mathrm{Al}$ is found to exhibit significant softening during in situ nanoindentation with anodization processing. Compared with ex situ nanoindentation without anodization processing, the in situ hardness measured on the alumina is found to be much lower, when the estimated maximum stress underneath the indenter is exerted on the metal/ oxide $(\mathrm{m} / \mathrm{o})$ interface at the bottom of the oxide. Numerical calculation reveals that a high electric field exists across the nanometrically thin barrier layer where the electrochemical reactions mainly take place. In microindentation with a flat punch, in situ softening is also observed, but no significant difference in the deformation of the oxide and the $\mathrm{Al}$ substrate between in situ and ex situ cases can be observed from cross-sectional transmission electron microscopy examination. The evidence, therefore, indicates that the observed in situ softening is due to a combination of high compression stress and electric field acting near the m/o interface, and it is likely that such conditions enhance $\mathrm{Al}$ ionization at the m/o interface, thus causing the m/o interface to move faster into the Al substrate under the in situ condition. (C) 2013 AIP Publishing LLC. [http://dx.doi.org/10.1063/1.4803865]
\end{abstract}

\section{INTRODUCTION}

Metals such as aluminum and titanium can form a porous anodic oxide layer on the surface with a quasihexagonal arrangement of the nano-pore-channels during anodization. $^{1-5}$ Such a form of oxide has previously been used as protective layers against corrosion, ${ }^{6}$ and recently been extensively employed as templates for the fabrication of nanomaterials with regular nanoelement arrays for applications including optics, ${ }^{7}$ electronics, ${ }^{8}$ magnetic memories, ${ }^{9}$ biodevices, ${ }^{10}$ and so on. The mechanical behavior of these porous oxides is also interesting and important. For example, Xia et al. found that when porous alumina was indented, the nanopores collapsed in a shear-band deformation mode rather than by crack formation and propagation in the structure, suggesting that the material can have multi-axial damage tolerance where the pores greatly improve the material's toughness. ${ }^{11,12} \mathrm{Ng}$ and Ngan demonstrated that the hardness of porous alumina increases significantly with the regularity of the porous pattern. ${ }^{13-16}$

However, in these previous investigations, the mechanical tests performed were all ex situ after the anodic porous alumina has already been fabricated by anodization. In situ mechanical tests during the growth of the oxide by anodization would be an interesting experiment to perform, since the mechanical stress and electrochemical reactions involved may exhibit coupling effects which have not been revealed before. In this paper, we carried out in situ nanoindentation on anodic porous alumina during anodization of $\mathrm{Al}$ in a specially designed electrochemical cell. For comparison, ex situ

\footnotetext{
a) Author to whom correspondence should be addressed. Electronic mail: chuan.cheng.research@gmail.com.
}

nanoindentation with the anodic current switched off was also carried out under comparable conditions. A novel softening effect during in situ nanoindentation compared with the ex situ case was found. In the following, after reporting the experiments and results, possible reasons for the in situ softening are suggested and analyzed.

\section{EXPERIMENTAL METHOD}

\section{A. Aluminium pre-treatment}

99.99\% pure aluminum foils were used for the nanoindentation tests. The $\mathrm{Al}$ specimens were cut into disks of 1 in. in diameter and $1 \mathrm{~mm}$ in thickness. Before testing, the specimens were first annealed under a vacuum of $\sim 10^{-5}$ Torr at $500{ }^{\circ} \mathrm{C}$ for $48 \mathrm{~h}$, then mechanically polished with 1200 , 2400, 4000 grit SiC sandpapers and $6 \mu \mathrm{m}, 1 \mu \mathrm{m}$ diamond pastes in succession, and finally electropolished in a mixture solution of $\mathrm{HClO}_{4}\left(60 \%\right.$ wt.) and $\mathrm{C}_{2} \mathrm{H}_{5} \mathrm{OH}$ in $1: 4$ ratio by volume under $20 \mathrm{~V}$ at about $-10^{\circ} \mathrm{C}$ for $2 \mathrm{~min}$. The final grain size as measured by electron back-scatter diffraction (EBSD) was about $1 \mathrm{~mm}$.

\section{B. Electrochemical cell setup}

To enable anodization to be carried out in the nanoindentation platform, a small cylindrical electrochemical cell was made from polymethyl methacrylate to fit into the space between the sample stage and the transducer of the nanoindenter, as shown in Fig. 1(a). Here, a copper plate connected to an outside power supply was used to support the aluminum disk which acted as the anode. The copper plate was first mounted into an acrylic hot-mounting resin cylinder of $1 \mathrm{in}$. in diameter, and then the cylindrical assembly was 
(a)

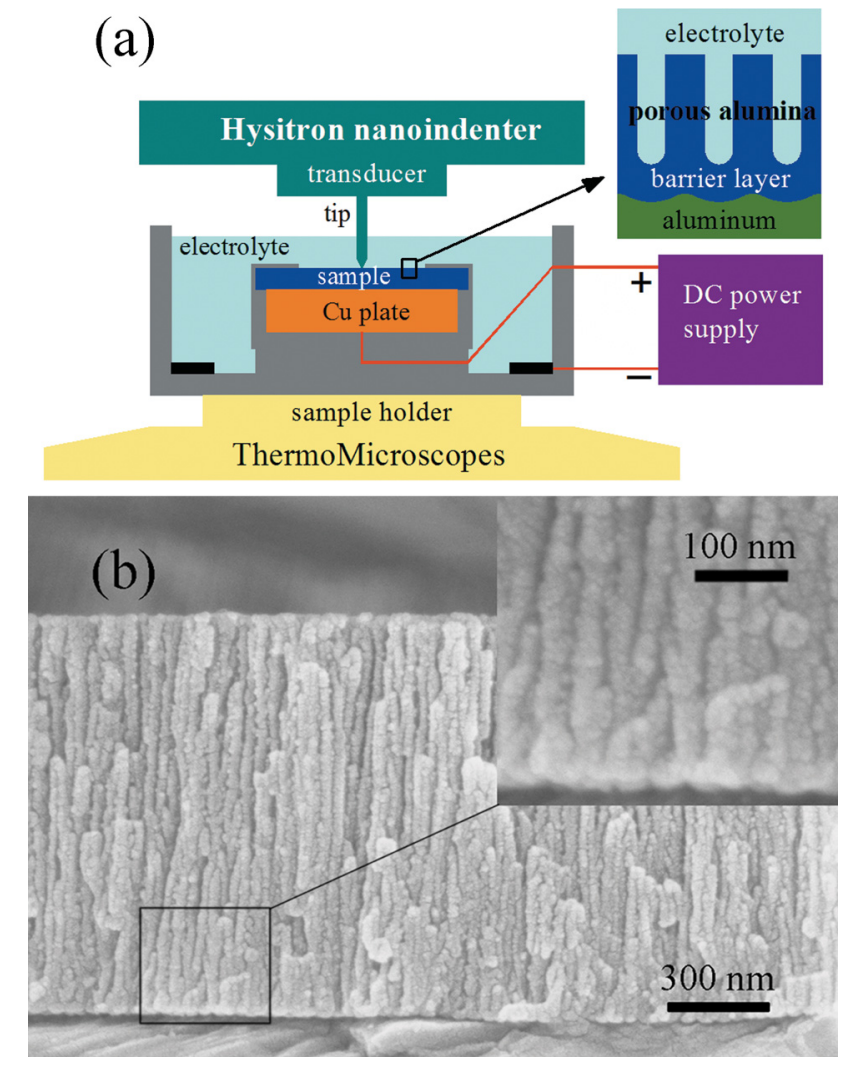

FIG. 1. (a) Schematic of experimental setup for nanoindentation on anodic porous alumina. (b) Cross-section view of anodic porous alumina formed during nanoindentation under the anodization condition of $20 \mathrm{~V}, 0.2 \mathrm{M}$ $\mathrm{H}_{2} \mathrm{C}_{2} \mathrm{O}_{4}$, room temperature, and $21.5 \mathrm{~min}$.

attached to the bottom center of the cell. The Al specimen was attached to the copper plate using conductive epoxy, and then the circular rim between the $\mathrm{Al}$ specimen and the cylinder was covered with a flexible rubber sleeve which was about $0.1 \mathrm{~mm}$ in thickness, so that only the central part of the Al specimen was exposed to the electrolyte. A copper wire hoop was attached to the bottom of the electrochemical cell and connected with the outside power supply to serve as the cathode. The specimen surface was about $2 \mathrm{~mm}$ below the free surface of the electrolyte.

\section{In situ and ex situ nanoindentations}

Nanoindentation was carried out on a Hysitron TriboScope nanoindenter (Hysitron Inc., Minneapolis, MN) mounted onto a ThermoMicroscopes scanning probe microscope. The indenter has a Berkovich tip designed for use in liquid (Hysitron Inc.). During in situ nanoindentation, anodization of $\mathrm{Al}$ was conducted in the electrochemical cell under $20 \mathrm{~V}, 0.2 \mathrm{M} \mathrm{H}_{2} \mathrm{C}_{2} \mathrm{O}_{4}$ (oxalic acid) electrolyte at room temperature. Under this condition, as illustrated in the top right of Fig. 1(a), porous-type anodic alumina is formed with nanosized pore channels growing vertically from the surface towards the Al substrate. The average oxide growth rate is about $0.89 \mathrm{~nm} \mathrm{~s}^{-1}$, as shown in Fig. 1(b).

In order to have a basis for comparison, ex situ nanoindentation was first conducted with the anodic current turned off, so that the indentation was made on the sample immersed in the electrolyte but without anodization processing. Immediately afterwards, in situ nanoindentation was conducted on a fresh location about $4 \mu \mathrm{m}$ away from the previous indent with the current turned on. After this, the current was turned off again for a second round of ex situ indentation on another location $4 \mu \mathrm{m}$ away. The sequence was then repeated. The same load function was used for both in situ and ex situ nanoindentations, and this consisted of a load ramp at $100 \mu \mathrm{N} \mathrm{s}^{-1}$ followed by a $5 \mathrm{~s}$ holding time at the maximum load $P_{\max }=500 \mu \mathrm{N}$. Although we set the duration of each nanoindentation to be $25 \mathrm{~s}$ in the load function, in practice, the Hysitron nanoindenter would add $1 \mathrm{~s}$ before loading and $4 \mathrm{~s}$ after unloading at the zero load, so that the real indentation period was $30 \mathrm{~s}$. Both the loading and unloading stages have a $5 \mathrm{~s}$ holding segment at $10 \% P_{\max }$ for drift correction. The used drift rate is the average of two drift rates measured from the two $5 \mathrm{~s}$ holding segments.

\section{In situ and ex situ microindentations}

In addition to nanoindentation with a Berkovich diamond tip, microindentation was also carried out on a Buehler Micromat 2100 hardness tester equipped with a diamond flat punch tip with diameter of $\sim 20 \mu \mathrm{m}$, which was made from a previous Vickers tip by focused ion beam (FIB) milling in a Quanta 200 3D dual beam FIB/Scanning electron microscopy (SEM) system operating at $30 \mathrm{kV}$ ion beam voltage. The loading rate of the microindentation was $19.61 \mathrm{mN} \mathrm{s}^{-1}$ with $40 \mathrm{~s}$ ( or $99 \mathrm{~s}$ ) holding at $P_{\max }=98.07 \mathrm{mN}$. Anodization was conducted under $60 \mathrm{~V}, 0.05 \mathrm{M} \mathrm{H}_{2} \mathrm{C}_{2} \mathrm{O}_{4}$ at room temperature in the same electrochemical cell (Sec. IIB). For example, after anodization for $300 \mathrm{~s}$, the anodic current was turned off and then ex situ microindentation was conducted without anodization processing. Immediately after that, in situ microindentation with anodic current on was conducted at a position about $100 \mu \mathrm{m}$ away from the ex situ impression. After that, the current was turned off and the indented specimen was removed from the electrochemical cell for characterization. The indented alumina was formed on the same (001) oriented $\mathrm{Al}$ grain, as detected by EBSD scanning of the $\mathrm{Al}$ both before anodization and after anodization/indentation by selectively dissolving the formed alumina on top, in a mixed solution of $\mathrm{H}_{2} \mathrm{CrO}_{4}, \mathrm{H}_{3} \mathrm{PO}_{4}$, and $\mathrm{H}_{2} \mathrm{O}$ at 1.8:6:92.2 by weight at $60^{\circ} \mathrm{C}$.

\section{E. Microscopic characterization}

SEM was carried out in a LEO 1530 field-emission microscope in order to observe the nanoindentation impressions. Cross-sections of the microindentation impressions were observed by transmission electron microscopy (TEM) carried out in a Philips Tecnai microscope operating at $200 \mathrm{kV}$. Cross-sectional TEM thin foils were cut from similar positions from the samples, with their long directions parallel to the [010] surface normal and the [101] tangential direction on the surface of the substrate Al grain, for both ex situ and in situ impressions, by FIB milling with the current varied from $7 \mathrm{nA}$ for initial coarse milling to $0.3 \mathrm{nA}$ for final fine milling. The orientation of the $\mathrm{Al}$ substrate was maintained the same, so that comparable diffraction conditions could be achieved in the TEM. Before cutting the TEM 
samples, the targeted area was deposited with a tungsten layer about $5 \mu \mathrm{m}$ thick to protect the porous alumina underneath.

\section{RESULTS AND DISCUSSION}

\section{A. Softening during in situ indentation}

Ex situ nanoindentation with anodic current off and in situ nanoindentation with current on were performed alternatively as described in Sec. II. After anodizing for $90 \mathrm{~s}$, the current was turned off, and then ex situ nanoindentation was performed to obtain the impression shown in Fig. 2(a): $90 \mathrm{~s}$. After that, the anodizing current was turned on, and in situ nanoindentation was performed to obtain the impression as shown in Fig. 2(b): 90+ s, with the anodization time reported as $90+\mathrm{s}$, where the " + " means that the anodization was still on-going during the in situ nanoindentation. This implies that the in situ indentation at $90+\mathrm{s}$ was performed on a slightly thicker oxide than the last ex situ indentation at $90 \mathrm{~s}$. Although a thicker oxide was indented in the in situ case, it is obvious that the resultant impression in Fig. 2(b): $90+\mathrm{s}$ is much larger than the ex situ one in Fig. 2(a): $90 \mathrm{~s}$, which implies a smaller hardness in the former. In Fig. 2(b): $90+$ s, the fracture of alumina during indentation is reflected as the pop-in of the load-depth curve shown in Fig. 2(d): 90+ s. As the anodization time increases, the thickness of anodic alumina also increases, and this is accompanied by a gradual reduction of the indent area for both ex situ (Fig. 2(a)) and in situ tests (Fig. 2(b)), but at the same time point the in situ nanoindent is always larger than that of the ex situ indents. Generally speaking, for indentation performed on a supported film, if the indentation depth to film thickness ratio is larger than 0.1, the substrate may influence the measured hardness. ${ }^{17}$ Here, the contact depth $\left(h_{c}\right)$ is obtained from the load-depth curves in Figs. 2(c) and 2(d), and the alumina thickness was evaluated as the product of the measured average oxide growth rate $\left(\sim 0.89 \mathrm{~nm} \mathrm{~s}^{-1}\right)$ and the total anodization time, counted as the sum of the durations when the anodization current was switched on, from the beginning of the experiment. From Fig. 2(e), the $h_{c}$ to oxide thickness ratio decreases quickly from 2.86 (in situ $60+\mathrm{s}$ ) and 2.28 (ex situ 60 s) to 0.17 (in situ 330+ s) and 0.16 (ex situ $330 \mathrm{~s}$ ), which are all larger than 0.1 . The reduction of the indent area as the oxide grows in thickness as seen in Figs. 2(a) and 2(b) indicates that the measured hardness is that for the oxide/Al composite, but the role of the $\mathrm{Al}$ substrate decreases quickly as the oxide thickens with increasing anodization time. The hardness difference between in situ and ex situ tests is reflected more clearly in the load-depth curves as shown in Figs. 2(c) and 2(d). The maximum and residual depths in the in situ indentation curves are all much larger than the corresponding ex situ cases, indicating that the hardness of the oxide/Al composite system under the in situ condition is much lower than that in the ex situ condition. In addition, within the same anodization time intervals, such as 90 to $150 \mathrm{~s}$, or 210 to $270 \mathrm{~s}$, the maximum or residual depth decreases much faster for the in situ case than the ex situ case. This is in accordance with the trend of the contact depth as shown in Fig. 2(e), implying that the influence of the $\mathrm{Al}$ substrate reduces faster in the in situ case.

The areas $A_{\mathrm{SEM}}$ of the indents as measured from the SEM micrographs were used to calculate the hardness of the sample according to

$$
H_{S E M}=\frac{P_{\max }}{A_{S E M}},
$$

where $P_{\max }$ is the maximum load. The hardness of the sample was also calculated by the Oliver-Pharr method ${ }^{18,19}$

$$
H_{O-P}=\frac{P_{\max }}{A_{c}\left(h_{c}\right)},
$$

(a)
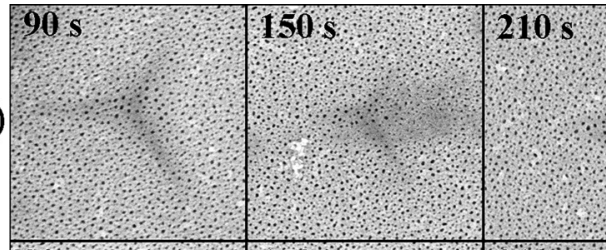

(b)
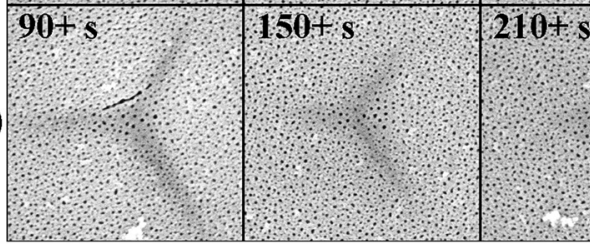

(c) ex situ $\rightarrow-90 \mathrm{~s}$

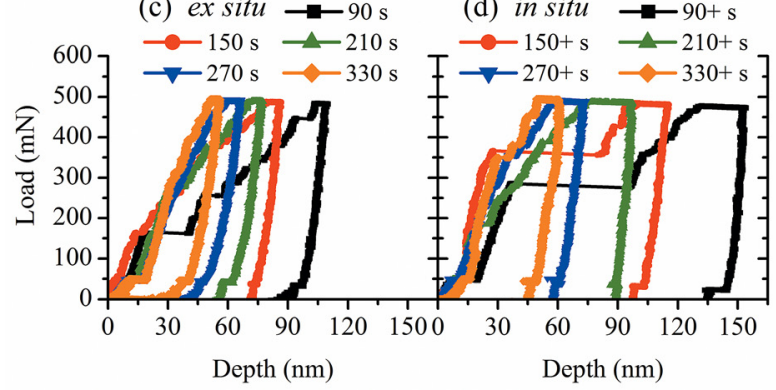

(d) in situ $\rightarrow-90+\mathrm{s}$
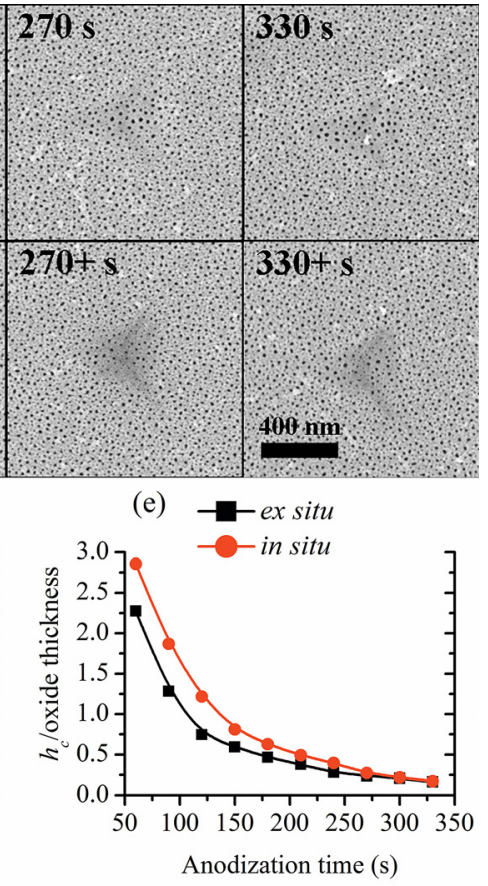

(e)

Anodization time $(\mathrm{s})$
FIG. 2. (a) SEM of ex situ nanoindentation impressions at anodization time of $90 \mathrm{~s}, 150 \mathrm{~s}, 210 \mathrm{~s}, 270 \mathrm{~s}$, and $330 \mathrm{~s}$, respectively. (b) SEM of in situ nanoindentation impressions at anodization time of $90+\mathrm{s}, 150+\mathrm{s}, 210+\mathrm{s}, 270+\mathrm{s}$, and $330+\mathrm{s}$, respectively, where "+" means anodization is on-going during the in situ nanoindentation. (c) and (d) Load-depth curves corresponding to impressions in (a) and (b), respectively. (e) Contact depth $\left(h_{c}\right)$ to oxide thickness ratio vs anodization time. All SEM figures have the same magnification. 

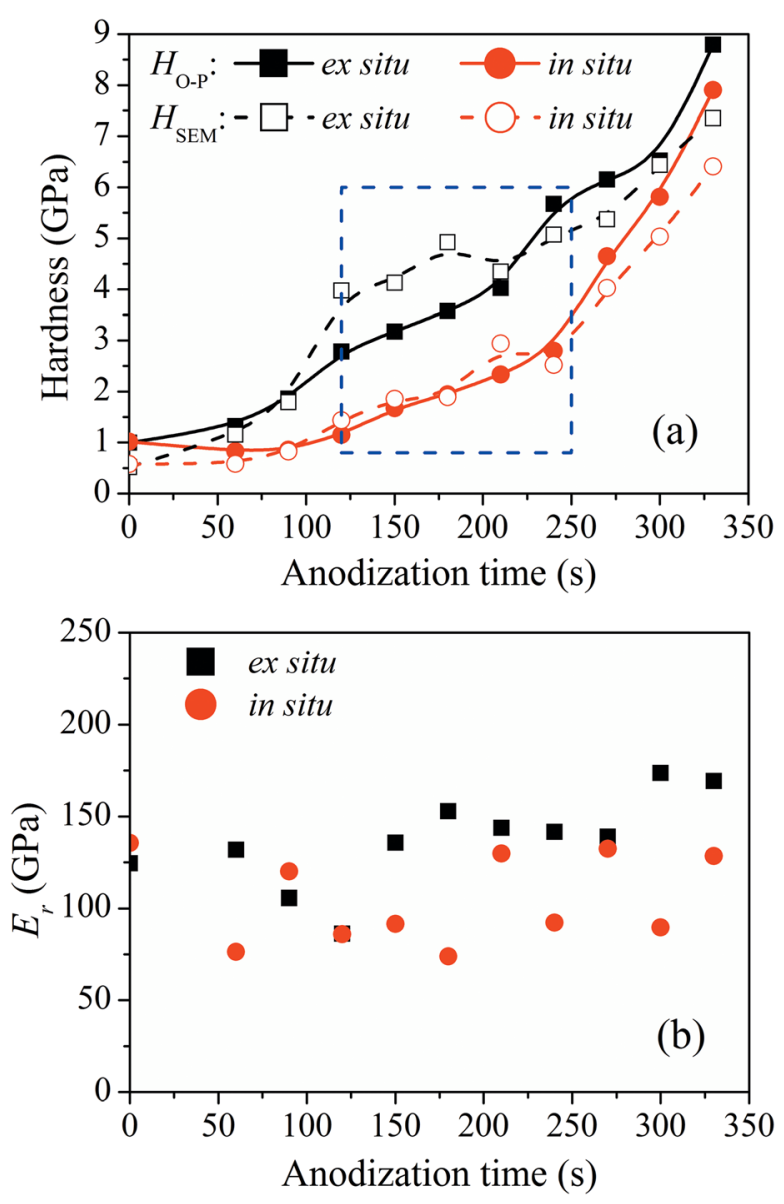

FIG. 3. (a) Hardness vs anodization time, where solid symbols and hollow symbols represent $H_{\mathrm{SEM}}$ and $H_{\mathrm{O}-\mathrm{P}}$, respectively. The dashed blue contour indicates an anodization time zone when the hardness difference between $e x$ situ and in situ nanoindentations is relatively large compared with other anodization time. (b) Measured reduced modulus $E_{\mathrm{r}}$ vs anodization time.

where $A_{c}$ is the contact area, which is a function of $h_{c}$ depending on the tip geometry. ${ }^{17}$ The $H_{\text {SEM }}$ and $H_{\text {O-P }}$ estimates of the hardness are plotted as a function of the anodization time in Fig. 3(a). Under both the in situ and ex situ conditions, the trends of the $H_{\mathrm{O}-\mathrm{P}}$ and $H_{\mathrm{SEM}}$ on increasing anodization time are in accordance with each other. Although some discrepancies exist between the $H_{\mathrm{SEM}}$ and $H_{\mathrm{O}-\mathrm{P}}$ values and these may be due to the SEM measured indent areas $A_{\mathrm{SEM}}$ not reflecting the porous structure of the oxide, ${ }^{15}$ both methods of calculation demonstrate that the in situ nanoindentation hardness is lower than the corresponding ex situ value at comparable anodization times. Moreover, the hardness difference between the in situ and ex situ cases is very small at the beginning stage $(t<60 \mathrm{~s})$ or the end stage $(t>300 \mathrm{~s})$ of anodization, but during an intermediate stage of $120 \mathrm{~s}<t<250 \mathrm{~s}$, as indicated by the blue-dashed box in Fig. 3(a), the in situ hardness is significantly lower than the ex situ hardness. The corresponding porous alumina thickness of the intermediate stage is about 107 to $223 \mathrm{~nm}$, and the $h_{c}$ to oxide thickness ratio (Fig. 2(e)) is about 1.22 to 0.39 for the in situ case, and 0.74 to 0.27 for the ex situ case. In addition, for both ex situ and in situ conditions, the measured hardness increases from the value for pure $\mathrm{Al}(\sim 0.6 \mathrm{GPa})^{20}$ towards that for pure porous alumina $(\sim 8 \mathrm{GPa})^{11}$ as the anodization time increases.
This implies the increasing contribution of the porous alumina layer to the measured hardness as the oxide thickens during anodization. Fig. 3(b) shows the reduced modulus $E_{\mathrm{r}}$ measured from load-depth curves using the Oliver-Pharr method. ${ }^{18,19}$ Although $E_{r}$ values do not vary much with anodization time for both in situ and ex situ cases, the $E_{\mathrm{r}}$ values of the in situ case are generally $32 \mathrm{GPa}$ lower than that of ex situ case. Here, the average ex situ $E_{r}$ is $137 \mathrm{GPa}$, which is close to previous results, such as the $140 \mathrm{GPa}$ by Xia et al. ${ }^{11}$ or $130 \pm 10 \mathrm{GPa}$ by Ko et al. ${ }^{21}$ But no in situ $E_{r}$ value has been reported before.

At the same anodization time, the key difference between in situ and ex situ nanoindentations is whether the anodization current is on or off. Thus, the softening observed during in situ nanoindentation has to be a result of the anodization current which passes through the specimen during the test. However, since the material system indented comprises a porous alumina layer on top and an $\mathrm{Al}$ substrate below, it is important to understand which component softens during anodization. From contact mechanics, the maximum shear stress underneath the indenter is $\tau_{\max } \approx 0.46 H$, where $H$ is the hardness, and this occurs at a depth $h_{\tau \text { max }}$ approximately 0.48 times the contact radius $a_{c}$ below the sample surface. $^{22,23}$ The contact radius $a_{c}$ can be estimated from the relationship $A_{c}=\pi a_{c}^{2} \approx 24.5 h_{c}^{2}$ for the a Berkovich tip, and so the position of $\tau_{\max }$ can be estimated as

$$
h_{\tau \max } \approx 1.34 h_{c} .
$$

The variation of $h_{\tau \max }$ with the anodization time is shown in Fig. 4(a). Also shown in Fig. 4(a) is the depth of the metal/ oxide (m/o) interface below the oxide's top surface, which appears as a sloping band with the same thickness $(26 \mathrm{~nm}$, under $20 \mathrm{~V}$ ) as the oxide barrier layer just above the $\mathrm{m} / \mathrm{o}$ interface. Because the $\mathrm{m} / \mathrm{o}$ interface is always in contact with the Al substrate, its position can be obtained from the porous oxide's thickness at each anodization time. From Fig. 4(a), there is a region of anodization time $(120 \mathrm{~s}<t<250 \mathrm{~s}$, labeled with blue dashed square) in which the most highly stressed location approximately overlaps with the m/o interface. This region coincides with the same time region plotted in Fig. 3(a) (also labeled with blue dash square), during which the most significant hardness reduction is observed during in situ nanoindentation compared with ex situ nanoindentation. This suggests whenever the $\tau_{\max }$ is exerted close to the m/o interface, a significant reduction of in situ hardness compared with ex situ hardness is detected by nanoindentation. The results here suggest that, with the anodization current on, softening mainly happens near the m/o interface.

\section{B. Possible explanations of the in situ softening}

The above softening during in situ indentation may be due to a number of reasons, which are discussed below.

\section{Electric-field assisted softening of oxide}

During anodization, an ultra-high electric field is expected to exist across the oxide barrier layer, ${ }^{24,25}$ which is a thin scallop shaped layer located along the m/o interface 

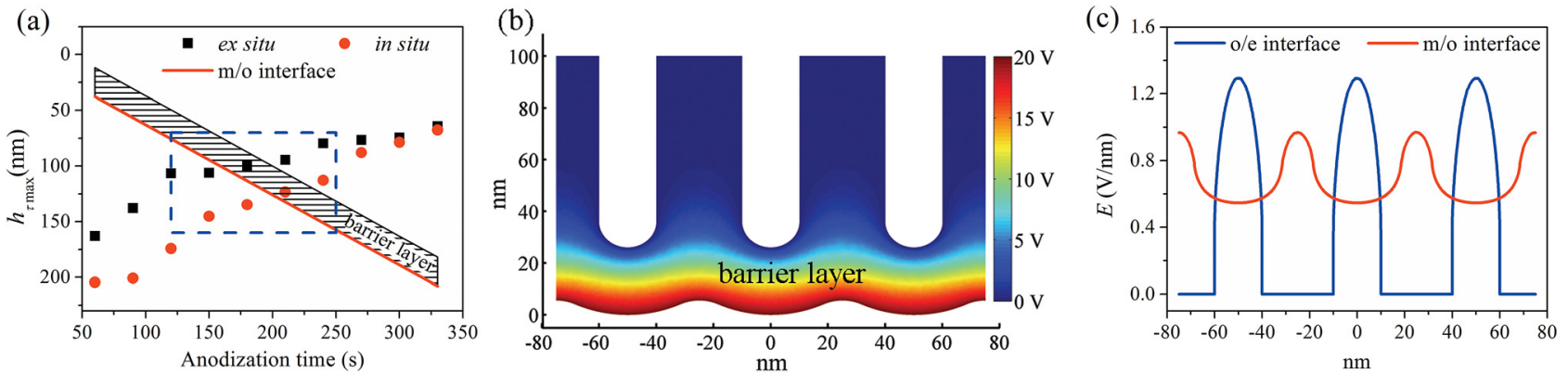

FIG. 4. (a) Maximum shear stress position and $\mathrm{m} / \mathrm{o}$ interface position below the sample surface vs anodization time. (b) Electric potential distribution in porous alumina during in situ nanoindentation. (c) Electric field intensity along oxide/electrolyte (o/e) and metal/oxide (m/o) interfaces, respectively.

with thickness proportional to the anodization voltage. ${ }^{26} \mathrm{We}$ have performed an analysis to predict the order of magnitude of the electric field within the oxide barrier layer during anodization. Following Parkhutik and Shershulsky ${ }^{27}$ and Singh et al. ${ }^{28}$ when space charge within the oxide and double layer effects at the interfaces are neglected, the electric potential $\varphi$ within the anodic alumina is governed by the Laplace equation

$$
\nabla^{2} \varphi=0,
$$

where $\nabla=(\partial / \partial x, \partial / \partial y)$ for the present two-dimensional (2-D) considerations. Equation (4) was solved by the finiteelement method within a 2-D domain, which represents the anodic alumina used in the nanoindentation. The boundary conditions are $\varphi=0$ at the o/e interface, $\varphi=20 \mathrm{~V}$ (the anodization voltage) at the $\mathrm{m} / \mathrm{o}$ interface, and $\mathbf{n} \cdot \nabla \varphi=0$ on the left and right sides, where $\mathbf{n}$ is the outward normal unit vector of the two sides of the domain. Numerical calculation was performed with a computer code developed from the MATLAB PDE toolbox..$^{29}$ Details on the simulation of the realtime growth of porous alumina during anodization can be found in our previous paper. ${ }^{24}$ As shown in Fig. 4(b), the electric potential drop mainly concentrates within the barrier layer, while within the finger-like pore-walls the drop is very weak. Accordingly, in Fig. 4(c), the electric field intensity $E=|\nabla \varphi|$ along o/e interface can reach a maximum value of $1.3 \mathrm{~V} \mathrm{~nm}^{-1}$ at the pore bottom, while along $\mathrm{m} / \mathrm{o}$ interface, a high value of $1.0 \mathrm{~V} \mathrm{~nm}^{-1}$ occurs at the ridges between two neighboring pores. Under such a high electric field intensity, high migration rates of $\mathrm{Al}^{3+}$ and $\mathrm{O}^{2-}$ ions across the barrier layer may happen, ${ }^{30,31}$ as the density of mobile ions was found to be exponentially proportional to the electric field intensity. ${ }^{30}$ Houser and Hebert theoretically proposed that during anodization, $\mathrm{Al}^{3+}$ and $\mathrm{O}^{2-}$ ions are transported by coupled electrical migration and viscous flow, and oxide flow arises near the oxide/electrolyte $(\mathrm{o} / \mathrm{e})$ interface at the pores' bottom. ${ }^{32}$ If oxide flow really exists, the mechanical strength of the oxide barrier layer should be greatly reduced, compared with the situation without anodization on-going.

\section{Enhancement of electrochemical reactions at $\mathrm{m} / \mathrm{o}$ interface}

A second consequence of the ultra-high electric field across the oxide barrier layer is that electrochemical reactions at the $\mathrm{m} / \mathrm{o}$ interface may be greatly enhanced. ${ }^{24,30,32}$ At the $\mathrm{m} / \mathrm{o}$ interface, $\mathrm{Al}$ ions are produced from $\mathrm{Al}$ substrate by ionization

$$
\mathrm{Al}_{(\mathrm{m})} \rightarrow \mathrm{Al}_{(\mathrm{ox})}^{3+}+3 \mathrm{e}^{-} .
$$

One portion of such $\mathrm{Al}^{3+}$ ions will form new oxide at the m/o interface according to

$$
2 \mathrm{Al}_{(\mathrm{ox})}^{3+}+3 \mathrm{O}_{(\mathrm{ox})}^{2-} \rightarrow \mathrm{Al}_{2} \mathrm{O}_{3(\mathrm{ox})}
$$

and the rest $(\sim 30 \%)$ of $\mathrm{Al}^{3+}$ will migrate across the barrier layer and then are ejected into the electrolyte without oxide formation. ${ }^{33,34}$ The needed $\mathrm{O}^{2-}$ ions in Eq. (6) come from the water decomposition at the o/e interface ${ }^{32}$ and then migration across the barrier layer to reach the $\mathrm{m} / \mathrm{o}$ interface. During in situ indentation, these reactions at the $\mathrm{m} /$ $o$ interface may be further enhanced, causing the $\mathrm{m} / \mathrm{o}$ interface to advance more quickly into the $\mathrm{Al}$ substrate and thus a softening effect. This possibility will be further discussed later.

\section{Enhancement of dislocation activities in Al substrate}

The oxidation reaction in Eq. (6), which takes place at the $\mathrm{m} / \mathrm{o}$ interface, is accompanied by volume expansion. ${ }^{35,36}$ The Pilling-Bedworth ratio ${ }^{35,36}$ after considering the $30 \%$ loss of $\mathrm{Al}^{3+}$ ions is

$$
\frac{(26.98 \mathrm{~g}+1.5 \times 15.99 \mathrm{~g}) / 3.0 \mathrm{~g} \mathrm{~cm}^{-3}}{26.98 \mathrm{~g} / 2.7 \mathrm{~g} \mathrm{~cm}^{-3}} \times(1-0.3)=1.19,
$$

which means $19 \%$ volume increase. This implies that large stresses may be created during in situ indentation at the $\mathrm{m} / \mathrm{o}$ interface, ${ }^{36}$ which may facilitate the deformation of the oxide barrier layer as well as the $\mathrm{Al}$ substrate just below the barrier layer, since the hardness of Al metal is more than 10 times smaller than that of the anodic alumina oxide. ${ }^{11,20}$ Moreover, as the electric current passes through the $\mathrm{Al}$ substrate, dislocation activities within it may be enhanced, resulting in softening compared with the situation without current passing. 


\section{TEM examination of deformation of oxide and $\mathrm{Al}$ substrate}

Explanation in Secs. III B 1 and III B 3 involves enhanced deformation of the oxide and dislocation plasticity at the $\mathrm{Al}$ substrate, respectively, and to examine whether these can actually occur, we performed in situ microindentation experiments on the anodic porous alumina during anodization using a flat punch indenter as shown in Fig. 5(a). Ex situ microindentation without anodization processing was also conducted for comparison. The anodization voltage was selected to be $60 \mathrm{~V}$ in order to obtain a relatively thicker barrier layer for better observation, according to the linear relationship between anodization voltage and barrier layer thickness. ${ }^{26}$ The electrolyte was $0.05 \mathrm{M} \mathrm{H}_{2} \mathrm{C}_{2} \mathrm{O}_{4}$ at room temperature. After anodization for $300 \mathrm{~s}$, the current was turned off, and then ex situ indentation was conducted to obtain the impression shown on the left hand side of Fig. 5(b). Immediately after that, in situ indentation with anodic current on was conducted to obtain the impression shown on the right hand side of Fig. 5(b). These two impressions were separated about $100 \mu \mathrm{m}$ apart, but they were on the oxide formed on the same (001) oriented Al grain, as confirmed by EBSD after selectively dissolving the anodic alumina on top. To observe the cross-sectional view of the impressions, TEM samples were cut by FIB milling at similar positions at the edge of each impression, as marked by black rectangles in Fig. 5(b). Figs. 5(c) and 5(d) show the TEM images of the cross-sectional view of the ex situ and in situ impressions, respectively. The tube like feathers were the anodic porous alumina, with the $\mathrm{Al}$ substrate below and the tungsten protective layer (black) on top. The residual depth for the ex situ indent is measured to be $2.45 \mu \mathrm{m}$, which is about $390 \mathrm{~nm}$ smaller than the $2.84 \mu \mathrm{m}$ of the in situ indent. This indicates that the in situ hardness is smaller than the ex situ hardness, which is in accordance with the nanoindentation results described in Sec. III A. From Figs. 5(c) and 5(d), plastic deformation mainly happened in the $\mathrm{Al}$ substrate below the alumina, while in the alumina brittle fracture happened only at the edge of each impression, and the reduction in the oxide thickness within the indented part relative to immediately outside the indent is rather mild, i.e., from $0.92 \mu \mathrm{m}$ to $0.80 \mu \mathrm{m}$ (a reduction by $120 \mathrm{~nm}$ ) for the ex situ case, and from $1.03 \mu \mathrm{m}$ to $0.72 \mu \mathrm{m}$ (a reduction by $310 \mathrm{~nm}$ ) for the in situ case, compared to indent depths between 2 and $3 \mu \mathrm{m}$. This situation is mainly due to the large difference in hardness between alumina and $\mathrm{Al}$ substrate, and in any case, the changes in thickness of the porous oxide layer between the in situ and ex situ cases are not large enough to account for the difference in indentation depths between the two cases.

Figures 5(e) and 5(f) show the cross-sectional view under the impressions near the oxide barrier layer in the ex situ and in situ cases, respectively. Again, no significant change in the thickness of the oxide barrier layer can be observed between the two cases; the barrier layer thicknesses for both the ex situ and in situ cases are measured to be $59 \pm 1 \mathrm{~nm}$, which is almost the same as that outside the indentation impressions. This may be because the $\mathrm{Al}$ substrate is very soft compared to the hardness of oxide barrier layer,
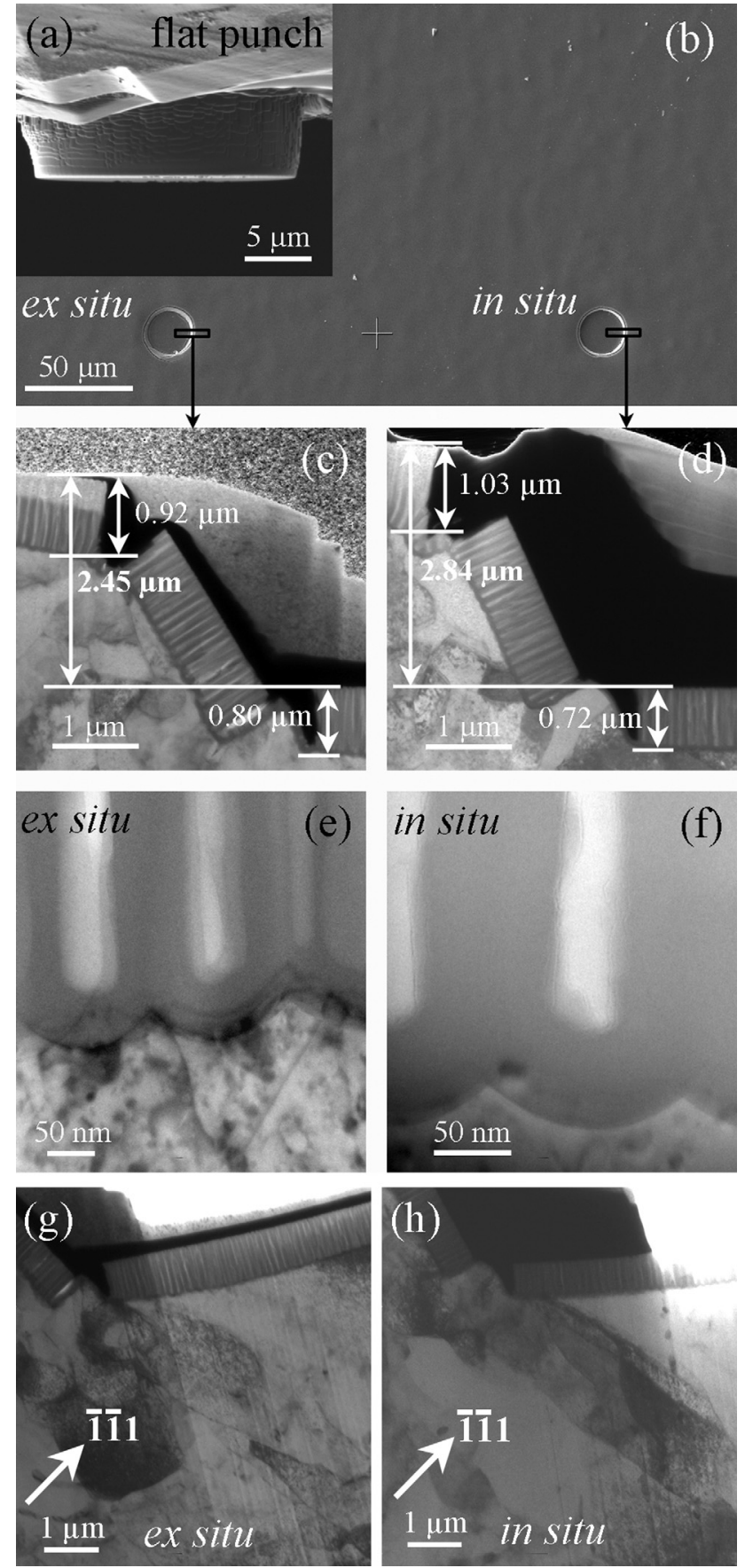

FIG. 5. (a) The diamond flat punch used in the microindentation. (b) Top view of the indentation impressions obtained by ex situ indentation at $\mathrm{t}=300 \mathrm{~s}$ (left hand side) and in situ indentation at $\mathrm{t}=300+\mathrm{s}$ (right hand side). The holding time is $40 \mathrm{~s}$ at the maximum load of $98.07 \mathrm{mN}$. TEM cross-sectional view of (c), (e), and (g) ex situ and (d), (f), and (h) in situ impressions. (c) and (d) The edges of impressions; (e) and (f) the m/o interface at the barrier layer of porous alumina underneath the impressions; (g) and (h) the Al substrate underneath the impressions. TEM images were taken at $\boldsymbol{g}=(\overline{1} \overline{1})$ near [101] pole for $(\mathrm{g})$ and $(\mathrm{h})$.

even with electrochemical reactions and ion migration taking place under the in situ case. Thus, the softening observed during in situ indentation is not due to a difference in the deformation of the oxide barrier layer of porous alumina. Figs. 5(g) and 5(h) show the deformation microstructures of the Al substrate in the ex situ and in situ cases, respectively, under the same electron diffraction condition $\boldsymbol{g}=(\overline{1} \overline{1} 1)$. 

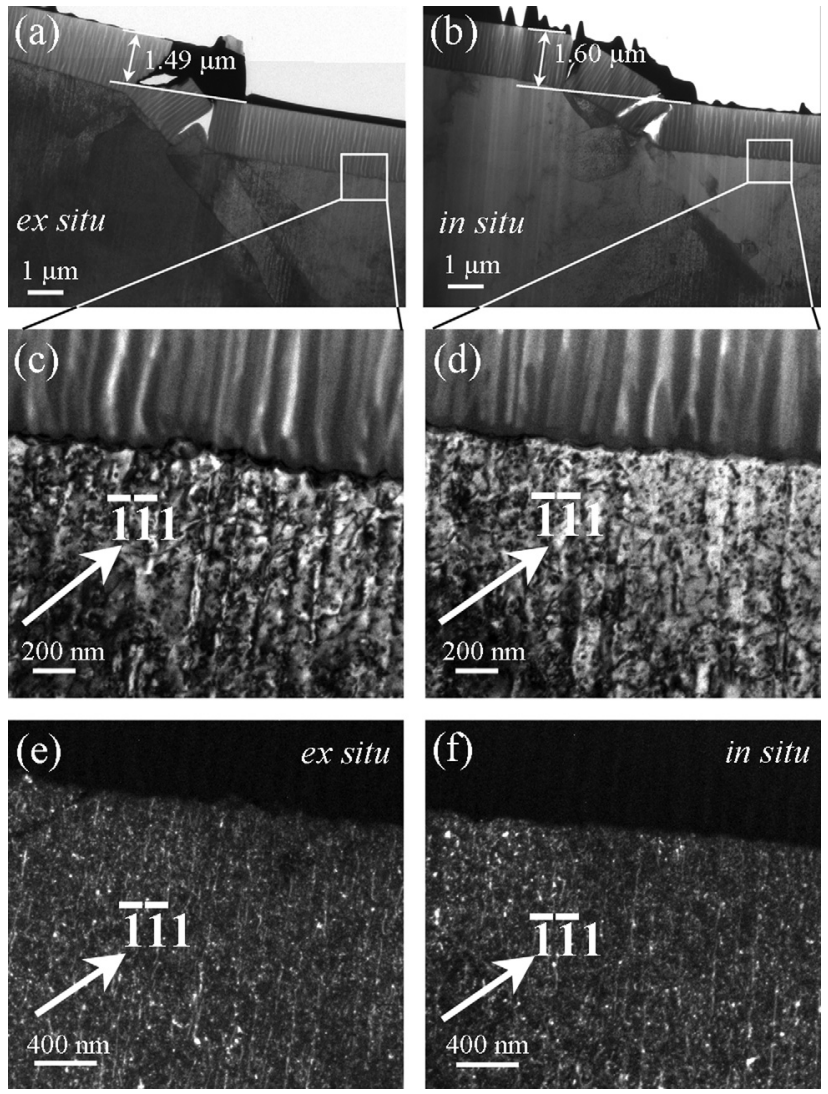

FIG. 6. (a) and (b) TEM cross-sectional view of flat punch microindentation impressions performed at $500 \mathrm{~s}$ and $500+\mathrm{s}$ under ex situ and in situ conditions, respectively. The holding time was $99 \mathrm{~s}$ at the maximum load of $98.07 \mathrm{mN}$. (c) and (d) Bright-field and (e) and (f) dark-field TEM crosssectional view of impressions around the metal/oxide interface underneath the (c) and (e) ex situ and (d) and (f) in situ impressions. All TEM images were taken at $\boldsymbol{g}=(\overline{1} 11)$ near [101] pole for (c)-(f).

In both cases, dense dislocation networks and subgrain formation can be seen in the Al substrate just underneath the indent, and there is no compelling evidence to indicate that dislocation activities in the $\mathrm{Al}$ substrate are more intensive in the in situ case than the ex situ case.

Figure 6 shows the TEM cross-sectional views of another pair of ex situ and in situ flat-punch microindentation impressions made on another specimen. This time, the holding time at the $P_{\max }$ was $99 \mathrm{~s}$ and before indentation the anodization had been on-going for $500 \mathrm{~s}$, but apart from these other conditions are the same as Fig. 5. As similar to Fig. 5, the in situ softening also occurred during microindentation, and from Figs. 6(c) and 6(d), significant deformation of the oxide barrier layer at the bottom of the porous alumina is also not observed for both the ex situ and in situ cases. From Figs. 6(c)-6(f), under the same electron diffraction condition of $\boldsymbol{g}=(\overline{1} \overline{1})$ near [101] pole, the dislocation density within the $\mathrm{Al}$ substrate, measured as the inverse-square of the average dislocation spacing, is of the same order of magnitude of $10^{15} \mathrm{~m} / \mathrm{m}^{3}$ in both the ex situ and in situ cases. Thus, Fig. 6 also indicates the in situ softening is neither due to the softening of the oxide barrier layer nor the $\mathrm{Al}$ substrate just underneath the in situ indented porous alumina.

\section{Enhancement of electrochemical reactions at the $\mathrm{m} / \mathrm{o}$ interface by high electric-field and stress}

The proposed mechanisms for the in situ softening in Sec. III B 1 and III B 3 have now been ruled out by the above TEM results. Recalling that in Fig. 4(a), in situ softening is significant only when the maximum stress under the impression is exerted at around the $\mathrm{m} / \mathrm{o}$ interface. Thus, as discussed in Sec. III B 2, the reason for the in situ softening is evidently related to the enhancement of certain electrochemical reactions that happen at the $\mathrm{m} / \mathrm{o}$ interface, by the presence of a combination of high stress and electric-field there. On the one hand, oxide formation in Eq. (6) would lead to propagation of the $\mathrm{m} / \mathrm{o}$ interface into the $\mathrm{Al}$ substrate, but this reaction should not be enhanced by a compressive mechanical stress because of the volume expansion due to oxidization. A compressive mechanical stress would tend to suppress the volume expansion, so the oxidation reaction can only be retarded, rather than enhanced. For example in Fig. 5(d), during the in situ microindentation, a compression stress is exerted on the alumina during its growth by Eq. (6), while the Al substrate on either side, but not underneath the impression, should be subjected to tension due to the volume expansion of the oxide above. The oxide thickness underneath the impression is about $0.72 \mu \mathrm{m}$, which is $310 \mathrm{~nm}$ smaller than the thickness just outside the impression $(\sim 1.03 \mu \mathrm{m})$. This large difference was produced within a short microindentation duration of $50 \mathrm{~s}$, thus the retarding effect of a compressive stress on the oxidation reaction is rather large. Similarly, for the ex situ impression shown in Fig. 5(c), the oxide thickness within the impression region $(\sim 0.8 \mu \mathrm{m})$ is only about $120 \mathrm{~nm}$ smaller than that just outside the impression $(\sim 0.92 \mu \mathrm{m})$. This difference is much smaller than the in situ case of $310 \mathrm{~nm}$, as only the residual compression and tensile stresses play roles in the alumina growth after the ex situ impression has already been formed.

On the other hand, under in situ indentation, the ionization reaction of $\mathrm{Al}$ in Eq. (5) can be promoted by both a high electric field and compression stress. Underneath an in situ impression, high compressive stresses are present near the $\mathrm{m} / \mathrm{o}$ interface due to the volume expansion accompanying oxidation in Eq. (6), and also the indentation force. Therefore, when the maximum stress position of the indentation field overlaps with the m/o interface (Fig. 4(a)), the ionization reaction in Eq. (5) may be enhanced there by the compression stress, since $\mathrm{Al}$ atom ionized will be pumped across the oxide barrier layer into the electrolyte by the high electric field and stress in the barrier layer. In this way, Eq. (5) effectively serves as a relief mechanism for the compressive stress in the in situ case, and such a stress relief mechanism is not present in the ex situ condition. Therefore, during in situ indentation, $\mathrm{Al}$ atoms in the substrate are continuously lost into the electrolyte, while the remaining substrate also undergoes plastic deformation, but in the ex situ case, only plastic deformation can happen. As a result, the m/o interface in the in situ case should advance faster than the ex situ case, especially during the holding at the $P_{\max }$ of microindentation, and so the in situ indent depth becomes deeper, corresponding to the softening observed. 
No matter what the actual mechanism is, the chemomechanical softening observed from the present in situ indentation experiments is a novel phenomenon which may find applications in the future, including as an enhanced means for micro-stamping and micro-surface texturing of thin oxide films. The combined effects of high electric field and mechanical stresses on electrochemical reactions as well as plastic deformation near nano-scale interfaces are also an open area deserving more investigations in the future.

\section{CONCLUSIONS}

In situ nanoindentation hardness of anodic porous alumina supported on $\mathrm{Al}$ substrate during anodization is found to be significantly smaller than the ex situ hardness, in a window of anodization time within which the estimated position of the maximum stress in the indentation field overlaps with the position of the metal/oxide $(\mathrm{m} / \mathrm{o})$ interface. Numerical simulations show that during anodization, the electric field intensity in the barrier layer is at a high magnitude of $\sim 1 \mathrm{~V} \mathrm{~nm}^{-1}$. Cross-sectional TEM examination reveals that dislocation activities in the $\mathrm{Al}$ substrate, as well as the thickness of the oxide barrier layer, are similar in both the in situ and $e x$ situ indentation cases. The total oxide thickness in the in situ case is somewhat smaller, but the difference with the ex situ case is still not large enough to explain the softening observed. Summing up the evidence, the observed softening during in situ indentation is not due to enhanced deformation of the formed oxide or dislocation activities in the $\mathrm{Al}$ substrate, but is likely the result of enhanced $\mathrm{Al}$ ionization at the $\mathrm{m} / \mathrm{o}$ interface, due to a combined high electric field and compressive stress there.

\section{ACKNOWLEDGMENTS}

The work described in this paper was supported by grants from the Research Grants Council (Project No. HKU7159/10E), as well as from the University Grants Committee (Project No. SEG-HKU06) of the Hong Kong Special Administration Region, P.R. China.
${ }^{1}$ G. E. Thompson and G. C. Wood, Nature 290, 230 (1981).

${ }^{2}$ H. Masuda and K. Fukuda, Science 268, 1466 (1995).

${ }^{3}$ W. Lee, R. Ji, U. Gösele, and K. Nielsch, Nature Mater. 5, 741 (2006).

${ }^{4}$ Z. Su and W. Zhou, Adv. Mater. 20, 3663 (2008).

${ }^{5}$ C. K. Y. Ng and A. H. W. Ngan, Chem. Mater. 23, 5264 (2011).

${ }^{6}$ G. E. Thompson, Thin Solid Films 297, 192 (1997).

${ }^{7}$ H. Masuda, M. Yamada, F. Matsumoto, S. Yokoyama, S. Mashiko, M. Nakao, and K. Nishio, Adv. Mater. 18, 213 (2006).

${ }^{8}$ W. B. Choi, J. U. Chu, K. S. Jeong, E. J. Bae, J. W. Lee, J. J. Kim, and J. O. Lee, Appl. Phys. Lett. 79, 3696 (2001).

${ }^{9}$ W. Lee, H. Han, A. Lotnyk, M. A. Schubert, S. Senz, M. Alexe, D. Hesse, S. Baik, and U. Gösele, Nat. Nanotechnol. 3, 402 (2008).

${ }^{10}$ F. Matsumoto, K. Nishio, and H. Masuda, Adv. Mater. 16, 2105 (2004).

${ }^{11}$ Z. Xia, L. Riester, B. W. Sheldon, W. A. Curtin, J. Liang, A. Yin, and J. M. Xu, Rev. Adv. Mater. Sci. 6, 131 (2004).

${ }^{12}$ Z. Xia, L. Riester, W. A. Curtin, H. Li, B. W. Sheldon, J. Liang, B. Chang, and J. M. Xu, Acta Mater. 52, 931 (2004).

${ }^{13}$ K. Y. Ng and A. H. W. Ngan, Scr. Mater. 66, 439 (2012).

${ }^{14}$ K. Y. Ng, L. Zuo, and A. H. W. Ngan, Scr. Mater. 61, 955 (2009).

${ }^{15}$ K. Y. Ng, Y. Lin, and A. H. W. Ngan, Acta Mater. 57, 2710 (2009).

${ }^{16}$ S. Wang, A. H. W. Ngan, and K. Y. Ng, Scr. Mater. 67, 360 (2012).

${ }^{17}$ A. C. Fischer-Cripps, Nanoindentation, 2nd ed. (Springer, New York, 2004).

${ }^{18}$ W. C. Oliver and G. M. Pharr, J. Mater. Res. 7, 1564 (1992).

${ }^{19}$ W. C. Oliver and G. M. Pharr, J. Mater. Res. 19, 3 (2004).

${ }^{20}$ N. G. Chechenin, J. Bottiger, and J. P. Krog, Thin Solid Films 261, 228 (1995).

${ }^{21}$ S. Ko, D. Lee, S. Jee, H. Park, K. Lee, and W. Hwang, Thin Solid Films 515, 1932 (2006).

${ }^{22}$ A. Barnoush and H. Vehoff, Scr. Mater. 58, 747 (2008).

${ }^{23}$ K. L. Johnson, Contact Mechanics (Cambridge University Press, Cambridge, 2003).

${ }^{24}$ C. Cheng and A. H. W. Ngan, Electrochim. Acta 56, 9998 (2011).

${ }^{25}$ C. Cheng, K. Y. Ng, and A. H. W. Ngan, AIP Adv. 1, 042113 (2011).

${ }^{26}$ J. P. O'Sullivan and G. C. Wood, Proc. R. Soc. London, Ser. A 317, 511 (1970).

${ }^{27}$ V. P. Parkhutik and V. I. Shershulsky, J. Phys. D: Appl. Phys. 25, 1258 (1992).

${ }^{28}$ G. K. Singh, A. A. Golovin, and I. S. Aranson, Phys. Rev. B 73, 205422 (2006).

${ }^{29}$ MATLAB R2009a, version 7.8.0.347, The Mathworks Inc., 2009.

${ }^{30}$ M. M. Lohrengel, Mater. Sci. Eng. R. 11, 243 (1993).

${ }^{31}$ J. W. Diggle, T. C. Downie, and C. W. Goulding, Chem. Rev. 69, 365 (1969).

${ }^{32}$ J. E. Houser and K. R. Hebert, Nature Mater. 8, 415 (2009).

${ }^{33}$ J. Siejka and C. Ortega, J. Electrochem. Soc. 124, 883 (1977).

${ }^{34}$ C. Cherki and J. Siejka, J. Electrochem. Soc. 120, 784 (1973).

${ }^{35}$ R. E. Smallman and A. H. W. Ngan, Physical Metallurgy and Advanced Materials (Elsevier, Amsterdam, 2007).

${ }^{36}$ F. Li, L. Zhang, and R. M. Metzger, Chem. Mater. 10, 2470 (1998). 